Published in final edited form as:

Curr Opin Virol. 2014 June ; 0: 78-84. doi:10.1016/j.coviro.2014.03.009.

\title{
Mucosal vaccines against respiratory syncytial virus
}

\author{
Kejian Yang ${ }^{1,{ }^{*}}$ and Steven M Varga ${ }^{2,3,4}$ \\ ${ }^{1}$ Biomedical Research Models Inc., 10 New Bond Street, Worcester, MA 01606 \\ ${ }^{2}$ Interdisciplinary Graduate Program in Immunology, University of lowa, lowa City, IA 52242, USA \\ ${ }^{3}$ Department of Pathology, University of lowa, lowa City, IA 52242, USA \\ ${ }^{4}$ Department of Microbiology, University of lowa, lowa City, IA 52242, USA
}

\begin{abstract}
Respiratory syncytial virus (RSV) is a leading cause of severe respiratory disease in infants, young children, immune-compromised and elderly populations worldwide. Natural RSV infection in young children does not elicit long-lasting immunity and individuals remain susceptible to repeated RSV infections throughout life. Because RSV infection is restricted to the respiratory tract, an RSV vaccine should elicit mucosal immunity at upper and lower respiratory tracts in order to most effectively prevent RSV reinfection. Although there is no safe and effective RSV vaccine available, significant progress has been recently made in basic RSV research and vaccine development. This review will discuss recent advances in the identification of a new neutralizing antigenic site within the RSV fusion (F) protein, understanding the importance of mucosal immune responses against RSV infection, and the development of novel mucosal vaccination strategies.
\end{abstract}

\section{Introduction}

Human respiratory syncytial virus (RSV) is a leading cause for bronchiolitis and severe respiratory disease in infants, young children, immune-compromised and elderly populations [1-3]. RSV is responsible for an estimated 160,000 deaths worldwide annually. RSV has a linear single-stranded RNA genome with 10 genes encoding 11 proteins, including nonstructural proteins (NS1 and NS2), large polymerase (L), phosphoprotein (P), nucleocapsid $(\mathrm{N})$, matrix protein (M1), envelope glycoproteins ( $\mathrm{SH}, \mathrm{G}$ and $\mathrm{F}$ ), a transcription factor (M2-1) and an accessory protein (M2-2). The attachment (G) and fusion (F) surface glycoproteins have been considered as the two major protective antigens for eliciting neutralizing antibodies. The $\mathrm{G}$ protein is heavily glycosylated and involved in viral

(C) 2014 Elsevier B.V. All rights reserved

'Correspondence: Kejian Yang, Ph.D, Biomedical Research Models, Inc., 10 New Bond Street, Worcester, MA 01606, Tel: 508 459 7544, KYang@biomere.com.

Publisher's Disclaimer: This is a PDF file of an unedited manuscript that has been accepted for publication. As a service to our customers we are providing this early version of the manuscript. The manuscript will undergo copyediting, typesetting, and review of the resulting proof before it is published in its final citable form. Please note that during the production process errors may be discovered which could affect the content, and all legal disclaimers that apply to the journal pertain.

Conflict of interest

Dr. Kejian Yang is an employee of Biomedical Research Models Inc. (BRM). Dr. Steven Varga is an employee of University of Iowa. 
attachment to host cells. The F protein mediates cell fusion allowing entry of the virus into the cell cytoplasm and formation of syncytia.

Although RSV vaccine development has been conducted since the 1960s, there is still no safe and effective vaccine available. A formalin-inactivated RSV (FI-RSV) vaccine, tested in infants a half century ago, resulted in enhanced morbidity and two deaths after a subsequent exposure to a natural RSV infection [4,5]. The infants and children that received the FI-RSV vaccine exhibited a lower level of neutralizing antibodies following a natural infection. It is likely that the process of formalin inactivation may have altered the structure of the $\mathrm{F}$ and $\mathrm{G}$ glycoproteins, resulting in altered protein processing and the induction of a largely nonfunctional (i.e. non-neutralizing) antibody response [6].

There are currently no effective treatments for an ongoing RSV infection. A humanized monoclonal antibody specific to the F protein (Palivizumab) administered as monthly injections during RSV season can prevent lower respiratory infection and severe disease in infected infants. However, it does not prevent infection of the upper respiratory system and is not recommended for use in healthy infants [7,8]. In addition, due to the high costs, Palivizumab is not extensively used worldwide. Therefore, a safe and effective RSV vaccine is still a high priority.

Significant progress has been made recently in both basic RSV research and vaccine development. Work in animal models and results from human vaccine trials led to a greater understanding of RSV pathogenesis and the correlates of protective immunity $[3,8,9]$. Recent advances in RSV research has created new opportunities and renewed hope, despite the sophisticated nature and significant challenges posed by RSV vaccine development. Since RSV F protein is a very important neutralizing antigen to potentially induce mucosal immunity, this review will focus on discussing 1) a newly identified neutralizing antigenic site located within the RSV pre-fusion (F) protein conformation; 2) the importance of mucosal immunity against RSV infection; 3) mucosal vaccination strategies in current development.

\section{RSV fusion protein and identification of a new antigenic site in its pre- fusion state}

The RSV F protein is a type I integral membrane protein and serves as an important target antigen for neutralizing antibodies and antiviral $\mathrm{T}$ cell responses [10]. To become biologically active and functional, the RSV F glycoprotein $\left(\mathrm{F}_{0}\right)$ after synthesis releases pep27 (a length of peptide of 27 amino acids), following proteolytic digestion by the enzyme furin at the two cleavage sites RKRR136 and RAR/KR109. This generates the F2 and F1 subunits, which are linked via a disulfide bond, and exposes the hydrophobic fusion peptide at the newly created N-terminus of F1 subunit [11,12]. The F protein usually exists in a metastable, pre-triggered form on the surface of the virion in order to mediate membrane fusion and viral entry. Once triggered, RSV F undergoes a dramatic conformational extension that leads to the insertion of its hydrophobic fusion peptide into the target cell membrane ultimately folding back on itself to bring membranes together resulting in virushost cell fusion [13]. Upon triggering, the post-fusion F becomes stable and forms the "hat- 
pin"- shaped molecules aggregate as rosettes [13]. The RSV F2 subunit, not the attachment G protein, determines the specificity of RSV infection [14]. Therefore, $\mathrm{F}$ is a very important protein target for vaccine development. The wild-type RSV F gene cannot be efficiently expressed without the application of codon optimization and deletion of premature polyadenylation signals [15]. Successful expression and immunization with the F protein was shown to induce neutralizing antibody and antiviral $\mathrm{T}$ cell responses. Furthermore, broad cross-serotype protection was elicited, likely due to immune responses against highly conserved F protein sequences among RSV strains [16-19].

As compared to the immunogenic full length RSV F protein with the transmembrane domain and cytoplasmic tail, the ectodomain of the $\mathrm{F}$ protein (i.e. truncated $\mathrm{F}$ by removing the transmembrane domain and cytoplasmic tail) also contains the necessary amino acid sequence for multiple neutralizing epitopes. Deletion of the transmembrane domain and the fusion peptide makes the truncated F protein soluble and prevents aggregation [20]. By doing so, Swanson et al. engineered a stable, immunogenic post-fusion truncated F protein that was capable of eliciting a high level of neutralizing antibodies and significantly protected cotton rats from RSV challenge [21]. In addition, MeLellan et al. also determined that a similar truncated trimeric F protein missing residues 137-146 contains the critical neutralizing sites (i.e. I, II and IV) in the stabilized post-fusion F protein [22].

With regard to the antigenicity, early protein structure data obtained via electron microscopy suggested that pre-fusion and post-fusion F may be antigenically distinct [23]. To prevent RSV infection of the upper respiratory tract, the local neutralizing antibody should presumably bind the pre-fusion $\mathrm{F}$ instead of the post-fusion $\mathrm{F}$ antigen. However, it has been a significant challenge to produce a stabilized pre-fusion $\mathrm{F}$, due to its metastable nature. A recent exciting breakthrough has been the identification of the antigenic site $\varnothing$ (zero) within the pre-fusion F protein. This was discovered through multiple mutations of S190F-V207L to fill up the hydrophobic cavity and creation of disulfide-links S155C-S290C to improve the stability of the pre-fusion F protein [24,25]. The S155C-S290C mutation is critical as it locks the fusion peptide in the central cavity without distortion of the rest of the protein structure. A neutralizing antibody specific to this new antigenic site was found to recognize the pre-fusion F protein, but not the postfusion F protein. This may explain why highly neutralizing antibodies in human serum cannot be fully absorbed by the post-fusion $\mathrm{F}$ protein [26]. The stabilized pre-fusion F protein contains all four neutralizing antigen sites (i.e. $\varnothing$, I, II and IV) and can elicit potent neutralizing antibody responses up to 8 -fold higher than post-fusion F protein. In addition, this level of neutralizing antibody was 20 to 40 times higher than the protective threshold believed to be required in mice and macaques $[24,25]$.

The antigenicity of the RSV F protein is dependent on the stability of the protein structure. To form a stable trimer structure for the truncated F protein, it is necessary to add a trimeric motif, such as the T4 phage fibritin trimerization domain to the C-terminus of the ectodomain of the F protein $[22,27]$. However, the transmembrane domain of the F protein is critical to form stable and soluble post-fusion $\mathrm{F}$ rosettes after deletion of 10 amino acids from the fusion peptide at the $\mathrm{N}$ terminus of $\mathrm{F} 1$ subunit $[9,28]$. Based on the recent identification of the very potent neutralizing antigen site $\varnothing$ in the prefusion F, the next 
generation of RSV vaccine candidates should include the F protein expressed in the prefusion form.

\section{Importance of mucosal immunity against RSV infection}

Many pathogens including RSV access the body through the mucosal infection. Therefore, effective vaccines that protect at the mucosal port of entry are much needed $[29,30]$. The efficient induction of mucosal immune responses requires appropriate administration routes and specific adjuvants and/or delivery systems. In contrast to the parenteral route of immunization, mucosal vaccination is usually required to efficiently elicit protective immune responses at mucosal sites. Intranasal delivery is the most effective route to induce potent and broad mucosal immune responses at multiple mucosal sites as compared to other mucosal delivery routes $[31,32]$.

The four main categories of RSV vaccines include inactivated, live-attenuated, gene-based vectors, and subunit [33]. Live-attenuated RSV vaccines [34] administered intranasally, and a subunit RSV postfusion F protein vaccine adjuvanted with alum and delivered intramuscularly $[28,35]$ have been extensively evaluated in a number of clinical trials in recent years. The live-attenuated RSV vaccine administered intransally has the potential to induce a mucosal immune response. However, the response may be weaker in magnitude than that of natural infection due to loss of immunogenicity during the process of attenuation.

In addition to the route of administration, adjuvants are also critical for induction of mucosal immunity. Currently, there are three approved human vaccine adjuvants: alum, monophosphoryl lipid A (MPL) and MF59 (Europe). These adjuvants are primarily used for systemic immunizations. Unlike other adjuvants, MPL may be the only safe and effective adjuvant for mucosal RSV vaccine application in cotton rats [36]. Ideally, induction of a robust mucosal immune response greater in magnitude as compared to a natural infection would be very desirable and beneficial.

An ideal RSV vaccine is expected to generate local immune humoral responses which can protect both the upper and lower respiratory tracts. The inability to evoke a longlasting protective immune response to RSV infection in mice correlates with poor nasal antibody responses [37]. Durable protective antibody levels are not normally induced in children following primary RSV infection resulting in frequent reinfections. In addition, low RSVspecific nasal IgA against $\mathrm{F}$ and $\mathrm{G}$ was found to be a significant risk factor for RSV infection in adults [38]. Although substantial numbers of RSV-specific plasma cells were elicited and maintained in the bone marrow following RSV challenge in the mouse infection model, the plasma cell counts in the nasal-associated lymphoid tissue waned rapidly without being maintained after primary infection [37]. Therefore, the inability to generate a robust local mucosal immunity in the nasal tissue (i.e. generation of serum antibody alone without local immunity) may be insufficient to protect against RSV reinfection. Low nasal virus titer is correlated with high nasal IgA. However, the majority of nasal IgA antibody is directed against the $\mathrm{G}$ protein and with less targeting the $\mathrm{F}$ protein. 
In addition to humoral and mucosal immune responses, an antiviral $\mathrm{T}$ cell response is also necessary for long-term protection against RSV infection. New data collected from the elderly ( $>65$ years old) suggests that reduced numbers of functional memory $\mathrm{T}$ cells specific to the RSV F protein and functionally deficient RSV F-specific T cell responses can increase susceptibility to severe RSV infection in elderly adults [39].

\section{Mucosal immunization strategies against RSV infection}

The biggest challenge in the development of a successful RSV vaccine has been how to attain the right balance between safety and efficacy [8]. Durability and mucosal immunity are also critical attributes for a successful RSV vaccine. An array of novel mucosal vaccination strategies with different delivery systems, administration routes, and adjuvants have been developed in recent years (see Table 1).

The FI-RSV vaccine administered intramuscularly was shown to enhance disease in infants upon RSV infection. In contrast, a live-attenuated RSV vaccine is believed to be a safe choice and is expected to induce mucosal immunity [9]. There are several types of liveattenuated RSV vaccines such as cold-passaged ( $c p)$, temperature-sensitive $(t s)$, reverse genetic engineered (i.e. by point mutations or gene deletions), and recombinant live virus vector-based RSV vaccines using attenuated bovine RSV, parainfluenza virus or Sendai virus vectors [34]. It will be important to determine whether these live-attenuated RSV vaccines can generate higher and more durable mucosal immunity than that induced by a natural RSV infection.

Being delivered usually by systemic immunization, subunit protein-based RSV vaccines were proven safe in older children and adults, however their immunogenicity was modest and they failed to induce potent mucosal immunity $[40,41]$. Among the approved adjuvants, MPL was tested as a mucosal immune modulator to enhance the immunogenicity of the ectodomain of $\mathrm{F}$ protein in cotton rats (i.n. primed and i.d. boosted) without inducing enhanced lung pathology [36].

These successes helped identify some promising mucosal vaccination strategies that may be potentially applicable to future RSV vaccine development. To induce mucosal immunity against RSV, a DNA vaccine prime (i.m., electroporation) and a recombinant adenovirus based-RSV F (tonsillar) prime-boost vaccination strategy was shown to be immunogenic in raising $\mathrm{T}$ cell responses and protection in the lower respiratory tract of adult rhesus macaques against RSV challenge [42]. However, recent adenovirus type-5 vector HIV vaccines have failed twice in clinical trials with either the adenovirus vector vaccine itself or as a booster following an initial DNA prime [43]. Whether either adenovirus type 5 or other types of adenovirus vectors will work as effective human RSV vaccine vectors remains to be determined.

Recombinant viral vector priming followed by either a subunit protein or a particle-based vaccine boost is regarded as a promising RSV vaccine approach for different target populations including infants $\leq 6$ months, 6 to 24 months and the elderly (>65 years) [9]. However, these approaches have inherent limitations such as anti-vector immunity and potentially virus vector specific safety issues. 
A lot of progress has been gained in recent years in our ability to elicit potent mucosal immune responses based experiences gained in developing many different mucosal delivery systems and the testing of non-RSV vaccine candidates in recent years (Table 1). A few of these non-viral vaccination strategies were shown to enhance mucosal, systemic antibody and $T$ cell responses against either mucosal infection or transmitted diseases [44-46]. As a heterologous prime and boost strategy, a variety of DNA prime and recombinant viral boost immunization platforms (e.g. such as vaccinia virus and adenovirus vectors) have been developed to enhance systemic immune responses. To raise potent humoral and $\mathrm{T}$ cellmediated immune responses systemically and at mucosal surfaces, Yang et al. developed a mucosal immunization regimen that avoids the use of viral vectors and bacterial toxin-based adjuvants yet induces potent immune responses both systemically and mucosally [47]. Using hepatitis B surface $\mathrm{Ag}$ (HBsAg), i.m. vaccination of BALB/c mice with a HBsAg-DNA vaccine prime followed by an i.n. boost with $\mathrm{HBsAg}$ protein encapsulated in biologically inert liposomes enhanced immune responses and protection, particularly on mucosal surfaces including nasal, lung and vaginal cavities. When an intranasal live virus challenge with a recombinant vaccinia virus expressing HBsAg was administered, immunized mice were completely protected without exhibiting lung pathology. This immunization strategy was also successful in raising synergistic immune responses systemically and mucosally in both adult and neonatal mice [45].

Furthermore, this mucosal heterologous vaccination strategy was successfully used to develop a HSV-2 vaccine expressing the immunogenic HSV-2 glycoprotein D. In female $\mathrm{BALB} / \mathrm{c}$ mice, this mucosal immunization regimen synergistically stimulated high level serum neutralizing antibodies, enhanced mucosal immune responses and potent protective immunity in the vaginal cavity, resulting in sterilizing immunity in $80 \%$ of mice. Durable protection in mice was demonstrated by a $60 \%$ survival rate, when lethal infections were performed 20 weeks after the initial immunization [44]. Currently, this proprietary platform technology is being used to develop a mucosal RSV vaccine.

In addition to humoral, cellular and mucosal immune responses, the relative balance in the $\mathrm{T}$ helper type response (Th1 vs. Th2) is believed to be very critical for the safety of an RSV vaccine. The failed FI-RSV vaccine induced an atypical Th2 response, while the response to RSV infection in mice has been characterized as a Th1 response with subsequent production of IFN- $\gamma$, IL-2, and IgG2 [48]. Part of the role of DNA vaccine priming in the heterologous DNA prime and protein/liposomal protein boost regimen is to dictate the ultimate $\mathrm{T}$ helper type outcome. The T helper response raised by DNA vaccine can be determined by the type of DNA expression vector, the form of antigen (i.e. membrane bound vs. truncated protein), and the route of administration and adjuvant. A recent study of DNA vaccines expressing the RSV F protein and truncated F protein in mice induced a Th1 and a balanced Th1/Th2 response, respectively [15]. Recent work has indicated that a significant benefit of a DNA vaccine prime followed by a protein boost is a dramatic improvement in the quality of the antibody response [49-52]. It would be very interesting to test if a heterologous DNA prime and liposomal protein boost strategy [44,47] is capable of inducing RSV antigen-specific mucosal immune responses and protection to a level higher than that of natural infection. 


\section{Conclusion}

RSV infection is the leading cause of pulmonary disease of the lower respiratory tract in infants. A safe and effective vaccine remains elusive. The recent identification of a new antigenic site in the stabilized pre-fusion $\mathrm{F}$ protein conformation has proven to be very immunogenic in raising very high neutralizing antibodies in two different animal species. In addition, recent clinical data suggest that the mucosal immune response, especially nasal IgA along with neutralizing antibody activities, is critically important to protect the upper and lower respiratory tracts against RSV infection. An array of novel mucosal vaccination strategies have been developed in recent years, some of them are directly used in RSV vaccine development and some of them originally developed for other mucosally transmitted diseases may be well suited as mucosal vaccination strategies for RSV. A new generation of safe and effective RSV vaccines may need to include the pre-fusion form of the RSV F protein in order to elicit potent and durable immune responses and protection especially at the upper and lower respiratory tracts.

\section{Acknowledgments}

Dr. Yang was supported by NIAID and CDC grants AI063820, AI102292, CCR922413 and CCR924378. Dr. Varga was supported by AI106776.

\section{References}

* of special interest

** of outstanding interest

1. Chanock R, Finberg L. Recovery from infants with respiratory illness of a virus related to chimpanzee coryza agent (cca). Ii. Epidemiologic aspects of infection in infants and young children. American journal of hygiene. 1957; 66(3):291-300. [PubMed: 13478579]

2. Chanock R, Roizman B, Myers R. Recovery from infants with respiratory illness of a virus related to chimpanzee coryza agent (cca). I. Isolation, properties and characterization. American journal of hygiene. 1957; 66(3):281-290. [PubMed: 13478578]

3. Graham BS, Anderson LJ. Challenges and opportunities for respiratory syncytial virus vaccines. Current topics in microbiology and immunology. 2013; 372(391-404)

4. Kapikian AZ, Mitchell RH, Chanock RM, Shvedoff RA, Stewart CE. An epidemiologic study of altered clinical reactivity to respiratory syncytial (rs) virus infection in children previously vaccinated with an inactivated rs virus vaccine. Am J Epidemiol. 1969; 89(4):405-421. [PubMed: 4305197]

5. Kim HW, Canchola JG, Brandt CD, Pyles G, Chanock RM, Jensen K, Parrott RH. Respiratory syncytial virus disease in infants despite prior administration of antigenic inactivated vaccine. Am J Epidemiol. 1969; 89(4):422-434. [PubMed: 4305198]

6. Murphy BR, Alling DW, Snyder MH, Walsh EE, Prince GA, Chanock RM, Hemming VG, Rodriguez WJ, Kim HW, Graham BS, et al. Effect of age and preexisting antibody on serum antibody response of infants and children to the $f$ and g glycoproteins during respiratory syncytial virus infection. Journal of clinical microbiology. 1986; 24(5):894-898. [PubMed: 3771779]

7. Blanken MO, Rovers MM, Molenaar JM, Winkler-Seinstra PL, Meijer A, Kimpen JL, Bont L. Respiratory syncytial virus and recurrent wheeze in healthy preterm infants. The New England journal of medicine. 2013; 368(19):1791-1799. [PubMed: 23656644]

8. Anderson LJ, Dormitzer PR, Nokes DJ, Rappuoli R, Roca A, Graham BS. Strategic priorities for respiratory syncytial virus (rsv) vaccine development. Vaccine. 2013; 31(Suppl 2):B209-B215. [PubMed: 23598484] 
9. Anderson LJ. Respiratory syncytial virus vaccine development. Seminars in immunology. 2013; 25(2):160-171. [PubMed: 23778071]

10. Brock SC, Heck JM, McGraw PA, Crowe JE Jr. The transmembrane domain of the respiratory syncytial virus $\mathrm{f}$ protein is an orientation-independent apical plasma membrane sorting sequence. Journal of virology. 2005; 79(19):12528-12535. [PubMed: 16160180]

11. Zimmer G, Budz L, Herrler G. Proteolytic activation of respiratory syncytial virus fusion protein. Cleavage at two furin consensus sequences. The Journal of biological chemistry. 2001; 276(34): 31642-31650. [PubMed: 11418598]

12. Zimmer G, Conzelmann KK, Herrler G. Cleavage at the furin consensus sequence rar/kR109) and presence of the intervening peptide of the respiratory syncytial virus fusion protein are dispensable for virus replication in cell culture. Journal of virology. 2002; 76(18):9218-9224. [PubMed: 12186905]

13. Chaiwatpongsakorn S, Epand RF, Collins PL, Epand RM, Peeples ME. Soluble respiratory syncytial virus fusion protein in the fully cleaved, pretriggered state is triggered by exposure to low-molarity buffer. Journal of virology. 2011; 85(8):3968-3977. [PubMed: 21307202]

14. Schlender J, Zimmer G, Herrler G, Conzelmann KK. Respiratory syncytial virus (rsv) fusion protein subunit $\mathrm{f} 2$, not attachment protein $\mathrm{g}$, determines the specificity of rsv infection. Journal of virology. 2003; 77(8):4609-4616. [PubMed: 12663767]

15. Ternette N, Tippler B, Uberla K, Grunwald T. Immunogenicity and efficacy of codon optimized DNA vaccines encoding the f-protein of respiratory syncytial virus. Vaccine. 2007; 25(41):72717279. [PubMed: 17825960]

16. Hurwitz JL. Respiratory syncytial virus vaccine development. Expert review of vaccines. 2011; 10(10):1415-1433. [PubMed: 21988307]

17. Rudraraju R, Jones BG, Sealy R, Surman SL, Hurwitz JL. Respiratory syncytial virus: Current progress in vaccine development. Viruses. 2013; 5(2):577-594. [PubMed: 23385470]

18. Jones BG, Sealy RE, Rudraraju R, Traina-Dorge VL, Finneyfrock B, Cook A, Takimoto T, Portner A, Hurwitz JL. Sendai virus-based rsv vaccine protects african green monkeys from rsv infection. Vaccine. 2012; 30(5):959-968. [PubMed: 22119594] * Sendai virus based RSV vaccine immunized animals exhibited reduced RSV in the URT compared to controls, and complete protection against RSV in the LRT. There were no clinically relevant adverse events associated with vaccination either before or after challenge.

19. Zhan X, Hurwitz JL, Krishnamurthy S, Takimoto T, Boyd K, Scroggs RA, Surman S, Portner A, Slobod KS. Respiratory syncytial virus (rsv) fusion protein expressed by recombinant sendai virus elicits b-cell and t-cell responses in cotton rats and confers protection against rsv subtypes a and $b$. Vaccine. 2007; 25(52):8782-8793. [PubMed: 18037543]

20. Martin D, Calder LJ, Garcia-Barreno B, Skehel JJ, Melero JA. Sequence elements of the fusion peptide of human respiratory syncytial virus fusion protein required for activity. The Journal of general virology. 2006; 87(Pt 6):1649-1658. [PubMed: 16690930]

21. Swanson KA, Settembre EC, Shaw CA, Dey AK, Rappuoli R, Mandl CW, Dormitzer PR, Carfi A. Structural basis for immunization with postfusion respiratory syncytial virus fusion $\mathrm{f}$ glycoprotein (rsv f) to elicit high neutralizing antibody titers. Proceedings of the National Academy of Sciences of the United States of America. 2011; 108(23):9619-9624. [PubMed: 21586636]

22. McLellan JS, Yang Y, Graham BS, Kwong PD. Structure of respiratory syncytial virus fusion glycoprotein in the postfusion conformation reveals preservation of neutralizing epitopes. Journal of virology. 2011; 85(15):7788-7796. [PubMed: 21613394]

23. Calder LJ, Gonzalez-Reyes L, Garcia-Barreno B, Wharton SA, Skehel JJ, Wiley DC, Melero JA. Electron microscopy of the human respiratory syncytial virus fusion protein and complexes that it forms with monoclonal antibodies. Virology. 2000; 271(1):122-131. [PubMed: 10814577]

24. McLellan JS, Chen M, Joyce MG, Sastry M, Stewart-Jones GB, Yang Y, Zhang B, Chen L, Srivatsan S, Zheng A, Zhou T, et al. Structure-based design of a fusion glycoprotein vaccine for respiratory syncytial virus. Science. 2013; 342(6158):592-598. [PubMed: 24179220] ** The metastable site specific to the prefusion state of the RSV fusion (F) glycoprotein is targeted by extremely potent RSV-neutralizing antibodies. Structure-based design yielded stabilized versions of RSV F that maintained this new antigenic site zero when exposed to extremes of $\mathrm{pH}$, 
osmolality, and temperature. Immunization with site zero stabilized variants of RSV F in mice and macaques elicited levels of RSV-specific neutralizing activity many times the protective threshold.

25. McLellan JS, Chen M, Leung S, Graepel KW, Du X, Yang Y, Zhou T, Baxa U, Yasuda E, Beaumont T, Kumar A, et al. Structure of rsv fusion glycoprotein trimer bound to a prefusionspecific neutralizing antibody. Science. 2013; 340(6136):1113-1117. [PubMed: 23618766] ** The prefusion state of respiratory syncytial virus (RSV) fusion (F) glycoprotein is the target of most RSV-neutralizing activity in human sera, but its metastability has hindered characterization. Several prefusion-specific antibodies that were substantially more potent than the prophylactic antibody palivizumab were identified. The cocrystal structure for one of these antibodies, D25, in complex with the F glycoprotein revealed D25 to lock F in its prefusion state by binding to a quaternary epitope at the trimer apex. The new antigenic side is named as antigenic site 0 .

26. Magro M, Mas V, Chappell K, Vazquez M, Cano O, Luque D, Terron MC, Melero JA, Palomo C. Neutralizing antibodies against the preactive form of respiratory syncytial virus fusion protein offer unique possibilities for clinical intervention. Proceedings of the National Academy of Sciences of the United States of America. 2012; 109(8):3089-3094. [PubMed: 22323598]

27. Zhou T, Xu L, Dey B, Hessell AJ, Van Ryk D, Xiang SH, Yang X, Zhang MY, Zwick MB, Arthos J, Burton DR, et al. Structural definition of a conserved neutralization epitope on hiv-1 gp120. Nature. 2007; 445(7129):732-737. [PubMed: 17301785]

28. Smith G, Raghunandan R, Wu Y, Liu Y, Massare M, Nathan M, Zhou B, Lu H, Boddapati S, Li J, Flyer D, et al. Respiratory syncytial virus fusion glycoprotein expressed in insect cells form protein nanoparticles that induce protective immunity in cotton rats. PloS one. 2012; 7(11):e50852. [PubMed: 23226404]

29. Lycke N. Recent progress in mucosal vaccine development: Potential and limitations. Nat Rev Immunol. 2012; 12(8):592-605. [PubMed: 22828912]

30. Holmgren J, Svennerholm AM. Vaccines against mucosal infections. Curr Opin Immunol. 2012; 24(3):343-353. [PubMed: 22580196]

31. Holmgren J, Czerkinsky C. Mucosal immunity and vaccines. Nature medicine. 2005; 11(4 Suppl):S45-S53. ** The properties of the mucosal immune system and advances in the development of mucosal vaccines for protection against infections were extensively discussed.

32. Rose MA, Zielen S, Baumann U. Mucosal immunity and nasal influenza vaccination. Expert review of vaccines. 2012; 11(5):595-607. [PubMed: 22827245]

33. Morrison TG, Walsh EE. Subunit and virus-like particle vaccine approaches for respiratory syncytial virus. Current topics in microbiology and immunology. 2013; 372:285-306. [PubMed: 24362695]

34. Karron RA, Buchholz UJ, Collins PL. Live-attenuated respiratory syncytial virus vaccines. Current topics in microbiology and immunology. 2013; 372:259-284. [PubMed: 24362694] * Advantages of live-attenuated respiratory syncytial virus (RSV) vaccines in infants and young children were discussed.

35. Glenn GM, Smith G, Fries L, Raghunandan R, Lu H, Zhou B, Thomas DN, Hickman SP, Kpamegan E, Boddapati S, Piedra PA. Safety and immunogenicity of a sf9 insect cell-derived respiratory syncytial virus fusion protein nanoparticle vaccine. Vaccine. 2013; 31(3):524-532. [PubMed: 23153449]

36. Blanco JC, Boukhvalova MS, Pletneva LM, Shirey KA, Vogel SN. A recombinant anchorless respiratory syncytial virus (rsv) fusion (f) protein/monophosphoryl lipid a (mpl) vaccine protects against rsv-induced replication and lung pathology. Vaccine. $2013 *$ The severe cytokine storm and pathology associated with RSV infection following intramuscular vaccination of cotton rats with FI-RSV Lot 100 could be completely abolished by formulating the vaccine with the mild TLR4 agonist and adjuvant, monophosphoryl lipid A (MPL). Despite this significant improvement, the vaccine failed to blunt viral replication in the lungs. A new vaccine preparation with purified, baculovirus expressed, partially purified, anchorless RSV F protein formulated with synthetic MPL was administered to cotton rats intranasally, followed by an intradermal boost. This formulation and heterologous"prime/boost" route of administration resulted in decreased viral titers compared to that seen in animals vaccinated with F protein alone. MPL acts as an immune modulator that protects the host from vaccine-enhanced pathology, and reduces RSV replication in the lower respiratory tract. 
37. Singleton R, Etchart N, Hou S, Hyland L. Inability to evoke a long-lasting protective immune response to respiratory syncytial virus infection in mice correlates with ineffective nasal antibody responses. Journal of virology. 2003; 77(21):11303-11311. [PubMed: 14557616] ** The inability to generate a robust local mucosal response in the nasal tissues may contribute substantially to the likelihood of subsequent reinfection and that the presence of serum anti- RSV antibody without local protection is not enough to protect against reinfection.

38. Walsh EE, Falsey AR. Humoral and mucosal immunity in protection from natural respiratory syncytial virus infection in adults. The Journal of infectious diseases. 2004; 190(2):373-378. [PubMed: 15216475] * Low RSV-specific nasal IgA was an independently significant risk factor for RSV infection in adults.

39. Cherukuri A, Patton K, Gasser RA Jr, Zuo F, Woo J, Esser MT, Tang RS. Adults 65 years old and older have reduced numbers of functional memory $t$ cells to respiratory syncytial virus fusion protein. Clinical and vaccine immunology : CVI. 2013; 20(2):239-247. [PubMed: 23239796]

40. Falsey AR, Walsh EE, Capellan J, Gravenstein S, Zambon M, Yau E, Gorse GJ, Edelman R, Hayden FG, McElhaney JE, Neuzil KM, et al. Comparison of the safety and immunogenicity of 2 respiratory syncytial virus (rsv) vaccines--nonadjuvanted vaccine or vaccine adjuvanted with alum--given concomitantly with influenza vaccine to high-risk elderly individuals. The Journal of infectious diseases. 2008; 198(9):1317-1326. [PubMed: 18855558]

41. Groothuis JR, King SJ, Hogerman DA, Paradiso PR, Simoes EA. Safety and immunogenicity of a purified $f$ protein respiratory syncytial virus (pfp-2) vaccine in seropositive children with bronchopulmonary dysplasia. The Journal of infectious diseases. 1998; 177(2):467-469. [PubMed: 9466539]

42. Grunwald T, Tenbusch M, Schulte R, Raue K, Wolf H, Hannaman D, de Swart RL, Uberla K, Stahl-Hennig C. Novel vaccine regimen elicits strong airway immune responses and control of respiratory syncytial virus in non-human primates. Journal of virology. 2014 Jan 22. [Epub ahead of print].

43. McMichael A, Picker LJ, Moore JP, Burton DR. Another hiv vaccine failure: Where to next? Nature medicine. 2013; 19(12):1576-1577.

44. Tirabassi RS, Ace CI, Levchenko T, Torchilin VP, Selin LK, Nie S, Guberski DL, Yang K. A mucosal vaccination approach for herpes simplex virus type 2. Vaccine. 2011; 29(5):1090-1098. [PubMed: 21134447]

45. Yang K, Whalen BJ, Tirabassi RS, Selin LK, Levchenko TS, Torchilin VP, Kislauskis EH, Guberski DL. A DNA vaccine prime followed by a liposome-encapsulated protein boost confers enhanced mucosal immune responses and protection. J Immunol. 2008; 180(9):6159-6167. [PubMed: 18424737]

46. Vajdy M, Baudner B, Del Giudice G, O'Hagan D. A vaccination strategy to enhance mucosal and systemic antibody and t cell responses against influenza. Clin Immunol. 2007; 123(2):166-175. [PubMed: 17349825]

47. Yang K, Whalen BJ, Tirabassi RS, Selin LK, Levchenko TS, Torchilin VP, Kislauskis EH, Guberski DL. A DNA vaccine prime followed by a liposome-encapsulated protein boost confers enhanced mucosal immune responses and protection. Journal of immunology. 2008; 180(9):61596167.

48. Domachowske JB, Rosenberg HF. Respiratory syncytial virus infection: Immune response, immunopathogenesis, and treatment. Clin Microbiol Rev. 1999; 12(2):298-309. [PubMed: 10194461]

49. Vaine M, Wang S, Liu Q, Arthos J, Montefiori D, Goepfert P, McElrath MJ, Lu S. Profiles of human serum antibody responses elicited by three leading hiv vaccines focusing on the induction of env-specific antibodies. PloS one. 2010; 5(11):e13916. [PubMed: 21085486]

50. Vaine M, Wang S, Hackett A, Arthos J, Lu S. Antibody responses elicited through homologous or heterologous prime-boost DNA and protein vaccinations differ in functional activity and avidity. Vaccine. 2010; 28(17):2999-3007. [PubMed: 20170767]

51. Vaine M, Wang S, Crooks ET, Jiang P, Montefiori DC, Binley J, Lu S. Improved induction of antibodies against key neutralizing epitopes by human immunodeficiency virus type 1 gp120 DNA prime-protein boost vaccination compared to gp120 protein-only vaccination. Journal of virology. 2008; 82(15):7369-7378. [PubMed: 18495775] 
52. Wang S, Parker C, Taaffe J, Solorzano A, Garcia-Sastre A, Lu S. Heterologous ha DNA vaccine prime--inactivated influenza vaccine boost is more effective than using DNA or inactivated vaccine alone in eliciting antibody responses against h1 or h3 serotype influenza viruses. Vaccine. 2008; 26(29-30):3626-3633. [PubMed: 18538900]

53. Schickli JH, Dubovsky F, Tang RS. Challenges in developing a pediatric rsv vaccine. Human vaccines. 2009; 5(9):582-591. [PubMed: 19556888]

54. Mok H, Lee S, Utley TJ, Shepherd BE, Polosukhin VV, Collier ML, Davis NL, Johnston RE, Crowe JE Jr. Venezuelan equine encephalitis virus replicon particles encoding respiratory syncytial virus surface glycoproteins induce protective mucosal responses in mice and cotton rats. Journal of virology. 2007; 81(24):13710-13722. [PubMed: 17928349] * RSV glycoproteinspecific virus neutralizing antibodies in serum and $\operatorname{IgA}$ antibodies were induced in secretions at the respiratory mucosa. In addition, fusion protein-encoding VRPs induced gamma interferon secreting $\mathrm{T}$ cells in the lungs and spleen. Close examination of histopathology of the lungs of vaccinated animals following RSV challenge revealed no enhanced inflammation. Immunization with VRPs induced balanced $\mathrm{Th} 1 / \mathrm{Th} 2$ immune responses, as measured by the cytokine profile in the lungs and antibody isotype of the humoral immune response.

55. Shafique M, Wilschut J, de Haan A. Induction of mucosal and systemic immunity against respiratory syncytial virus by inactivated virus supplemented with tlr9 and nod2 ligands. Vaccine. 2012; 30(3):597-606. [PubMed: 22120195]

56. Rigter A, Widjaja I, Versantvoort H, Coenjaerts FE, van Roosmalen M, Leenhouts K, Rottier PJ, Haijema BJ, de Haan CA. A protective and safe intranasal rsv vaccine based on a recombinant prefusion-like form of the $\mathrm{f}$ protein bound to bacterium-like particles. PloS one. 2013; 8(8):e71072. [PubMed: 23951084]

57. Cyr SL, Jones T, Stoica-Popescu I, Brewer A, Chabot S, Lussier M, Burt D, Ward BJ. Intranasal proteosome-based respiratory syncytial virus (rsv) vaccines protect balb/c mice against challenge without eosinophilia or enhanced pathology. Vaccine. 2007; 25(29):5378-5389. [PubMed: 17561317] 


\section{Highlights}

- New developments in RSV fusion (F) protein structure research.

- The importance of mucosal immunity in mediating protection against RSV infection.

- Mucosal RSV vaccine regimens currently in development. 
Table 1

Current mucosal RSV vaccination regimens

\begin{tabular}{|c|c|c|c|}
\hline Vaccine formulation & $\begin{array}{c}\text { Route of } \\
\text { administration }\end{array}$ & $\begin{array}{l}\text { Preclinical and } \\
\text { clinical studies }\end{array}$ & References \\
\hline $\begin{array}{c}\text { Attenuated RSV vaccines ( } c p, t s, \text { mutants by reverse } \\
\text { genetics) }\end{array}$ & Intranasal & $\begin{array}{l}\text { Mice, cotton rats and clinical } \\
\text { trials }\end{array}$ & {$[23,53]$} \\
\hline Attenuated sendai virus expressing RSV F & Intranasal & $\begin{array}{l}\text { Cotton rats and African green } \\
\text { monkeys }\end{array}$ & {$[16-19]$} \\
\hline $\begin{array}{l}\text { Venezuelan Equine Encephalitis virus replicons encoding } \\
\text { RSV glycoproteins }\end{array}$ & Intranasal & Mice and cotton rats & {$[54]$} \\
\hline $\begin{array}{c}\text { RSV F-DNA vaccine prime }+ \text { RSV F-adenovirus (Ad5) } \\
\text { boost }\end{array}$ & $\begin{array}{c}\text { Intrasmascular } \\
\text { electrophoration for DNA, } \\
\text { Tonsillar for RSVF-Ad5 }\end{array}$ & Rhesus macaques & {$[42]$} \\
\hline RSV ectodomain F + MPL & $\begin{array}{l}\text { Intranasal prime; } \\
\text { Intradermal boost }\end{array}$ & Cotton rats & {$[36]$} \\
\hline $\begin{array}{l}\text { Inactivated RSV supplemented with TLR9 and NOD3 } \\
\text { ligands }\end{array}$ & Intranasal & Mice & {$[55]$} \\
\hline Bacterium-like particle-based RSV F vaccine & Intranasal & Mice and cotton rats & {$[56]$} \\
\hline Proteosome adjuvanted RSV surface protein vaccine & Intranasal & Mice & {$[57]$} \\
\hline
\end{tabular}

